\title{
The Journal of the American Medical Association
}

\author{
Published Under the Auspices of the Board of Trustees
}

Vor. LXVII, No. 26

C H I C A G O, I L L I N O IS

DECEMBER 23, 1916

\section{IIEREDITARY SYPHILIS AS A CAUSE OF CHRONIC INVALIDISM}

AND TIE DIAGNOSIS BY INTENSIVE FAMJLIAL STUDY*

IENRY FARNUM STOLL, M.D.

Visiting Physician to the Home for Crippled Children, Newington; Assistant Physician, Hartford Hospital; Physician-in-Chief, Syphilis Clinic, Hartford Dispensary

IIARTFORD, CONN.

There is scarcely a symptom to which man is heir that may not be caused by the Spirochaeta pallida.

With the development of delicate laboratory tests the field is ever widening, and the syphilitic yardstick has been applied to practically every syndrome, with the result that we have been forced to change many of our ideas, and the end is not yet.

For many years certain clinicians have realized that syphilis is a disease of the family rather than of the individual; but it was not until the advent of the Wassermann test that it was appreciated how extensive prenatal infections are and that an apparently healthy child may harbor the organism.

Time causes certain changes in the spirochete in vitro; for example, the organism from a primary sore produces a lesion in a rabbit's testicle in from two to three weeks, while that obtained from general paresis requires three or four times as long to develop.

In like manner the symptoms occurring from twenty to thirty years after infection - especially prenatal infection-are often insidious of onset, vague and indefinite in their development, and quite frequently unaccompanied by physical signs. To obscure the condition further, the Wassermann test, so valuable in early syphilis, is only rarely positive in adults with hereditary syphilis.

For several years I have been interested in the study of syphilitic families; their symptoms have been analyzed, their physical signs tabulated whenever possible, and Wassermann tests made on many. I have been greatly assisted in this work by Miss Barry of the Hartford Visiting Nurses Association and Miss Goldberg at the Hartford Dispensary.

As a result of a more or less complete study of approximately 100 families, it has seemed to me that if one groups together all the symptoms and physical signs of all members of the family, certain syndromes will often be found that are quite suggestive of what might be termed familial syphilis.

The individual with tuberculosis usually presents a combination of symptoms and physical signs that are more or less typical of the disease. In "late" heredi-

* Read before the Section on Nervous and Mental Diseases at the ${ }^{*}$ Read before the Section on Nervous and Mental Diseases at the
Sixty-Seventh Annual Session of the Antrican Medical Association, Sixty-Seventh Annual
Detroit, June, 1916. tary syphilis, however, the patient may present no sign of syphilis and but a single obscure symptom which may be so distressing that a more or less complete invalidism results. But suspicious symptoms and perhaps conclusive physical signs may be found in other members of the family, and in this way a wholly indefinite and meaningless symptom, like one piece of a picture puzzle, may become highly significant when fitted into its right place in the family syndrome.

I judge that the diagnosis of hereditary syphilis by intensive familial study is not generally practiced, as no mention was made of it in four symposiums which I recently attended in which many well known syphilologists discussed the various problems of syphilis.

Family histories as commonly taken are entirely worthless in deciding for or against the possibility of familial syphilis. It takes a good deal of time to elicit all the facts; but not infrequently the information thus gained furnishes the only means of clearing up an obscare case.

Within a few days I examined a man whose father was stated to have died as the result of an accident. Inquiry developed that the accident was a gunshot wound through the mouth from which he made a good recovery, living many years thereafter and leading an active business life. About ten years before he died he developed some spinal trouble, which was attributed to his previous injury. He lost the use of his legs and got about only in a wheel-chair. This suggests that he may have had tabes, which would explain the high narrow palate I observed in his son and quite possibly the cerebral endarteritis from which he was suffering.

Before attempting to work out various syndromes of familial syphilis, one must first appreciate what diseases in a parent are indicative or highly suggestive of syphilis. We are justified in assuming syphilis when a parent has had tabes or paresis; as probable syphilis a history of aneurysm or aortic disease, and death from apoplexy and sudden heart failure before 50 ; as possibly syphilitic, cardiovascular renal deaths up to 60 or perhaps beyond. I also believe we are justified in at least suspecting syphilis in the presence of severe clíronic headaches not relieved by glasses. The parents may be living and said to be well; but a paralysis of the third or sixth nerves, insomnia, extreme nervousness or "rheumatism in the legs" should awaken our suspicions.

The second family cited illustrates the importance of minute inquiry as to the health of maternal aunts and uncles.

What is often referred to as the typical sequence of syphilitic pregnancies, namely, miscarriages, stillbirths, premature syphilitic children and finally healthy children, has in my experience been encountered only 
rarely. While syphilis is the most common cause of abortion, it should be realized that in certain syphilitic families all the pregnancies may result in living children. Syphilis is also a frequent cause of sterility; this seems especially liable to occur in the "weakling" group of heredosyphilitics. One should bear in mind that hereditary syphilis may have the same effect on the fetus that acquired syphilis has.

When pregnancy results in a syphilitic, one of several things may happen:

1. The fetus dies, and abortion or stillbirth results. This is usually attributed to a titerine malposition.

2. The fetus does not die, but is expelled prematurely.

3 . The child may $(a)$ present obvious evidence at birth or within a few weeks, or $(b)$ appear healthy for several years and then develop some syphilitic manifestations, as interstitial keratitis or a bone lesion.

4. Occasionally a healthy child is born to syphilitic parents whose disease is in a latent condition.

5. The child may exhibit certain stigmata, the result of protoplasmic disturbances, even when no infection occurs. I have had as patients two men with acquired syphilis with high narrow palates who were the sons of syphilitics. These dystrophies or alterations of the normal development of the germ plasm may be accompanied by a real congenital syphilitic infection. The

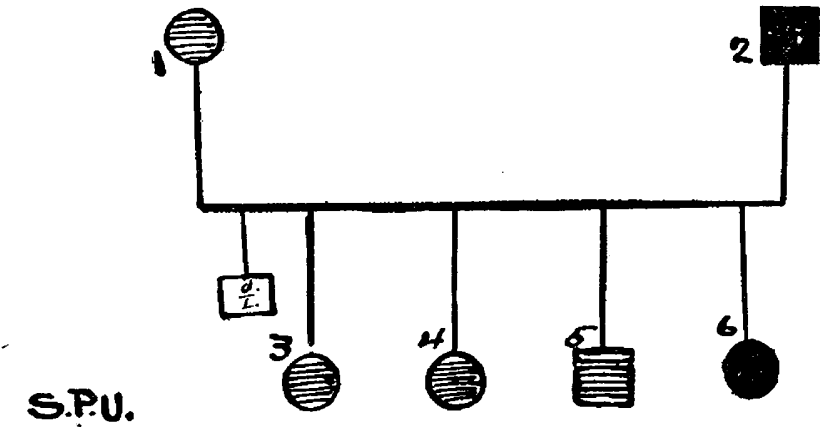

Chart 1.-Heredity chart, Family 1. In the charts, squares indicate male, and circles, female; all black, syphilis known to have been pres ent (except Chart 5, where solid black indicates epilepsy); shaded, probable sypbilis; triangle, miscarriage; double triangle, stillbirth; $d .1$. died in infancy; $H$, headache; $T B$, tuberculosis; $A$, alcoholic; $N$, ner votus; $S . P . U$, sequence of pregnancies uncertain. In the legends, $a$ indicates alive and $d$, dead. 1, $a$, alcoholic; headaches; $2, d$, tabe dorsalis; $3, a$, nervous; 4 , $a$, nervous; severe headaches; $5, a$, very nervous; $6, a$, chronic headache; spondylitis.

common dystrophies are the high narrow palate, hare lip, scaphoid scapulae, short arms, hypoplastic teeth, etc.

6. We should suspect the possibility of hereditary syphilis in individuals whose chief characteristic is a constitutional inferiority. As children they "took" everything and were always very ill. Even when not definitely sick they were ailing and "hard to raise," yet without definite reason. Usually nervous and irritable, frequently complaining of headache, they are prone develop tuberculosis which is apt to be fatal. Often a very thorough examination will reveal a suspicions sign, though sometimes we will find only the telltale dystrophy or symptom in a brother or sister.

It would be a very grave mistake to assume that all delicate children are heredosyphilitic. Nevertheless I am sure that too little attention has been paid to this particular disease as a cause of "weaklings."

As illustrative cases I have purposely chosen several who were free from the usual stigmata of hereditary syphilis and who had negative Wassermanns. Most of my tests were made in our state laboratory at Mid- dletown. A few, however, were made in reliable laboratories in New York and Philadelphia, and they too were negative.

The luetin test was positive in nearly all of the cases, but inasmuch as the specificity of this test has been seriously questioned in patients who have received potassium iodid, the results are not recorded, as nearly all had received this drug.

I personally feel that an intensive familial study of the supposedily nonspecific reactions will materially diminish their number.

\section{REPORT OF CASES}

CASE 1.-An unmarried woman of 26 (No. 6, Chart 1) complained of severe headaches from which she had suffered since earliest childhood. She was referred to me by Dr. Paul P. Swett, to whom she had been referred because of pain and tenderness of the upper cervical vertebrae. Dr. Charles A. McKendree, under whose care the patient was for a time at Cromwell Hall, kindly allowed me to supplement my history with his notes. She had been very strong as a child, but her headaches dated from her earliest recollection. She had always been of an excitable temperament, quíck and irritable. The headaches were so severe when the patient was 15 that she was forced to leave school, and consulted a number of eminent men in Europe after failing to obtain relief in this country. Each summer for the past thirteen years she had gone abroad, as the ocean trip helped her considerably. Two years ago a well known specialist in London did an extensive operation on the interior of the nose for the relief of the headaches, but without success. A roentgenogram revealed a tooth that had failed to erupt, and with the hope of obtaining relief it was removed, but no improvement followed.

The circumstances of the patient were such that she was able to consult many specialists of renown. Several Wassermann tests had been made, but all were negative. One neurologist had recently told her he was sorry her blood was negative, as otherwise he could have given her treatment. "I know you will be disgusted," he told her, "to have me say it is just 'nerves'." An interesting fact was elicited, however. Several years ago while in Germany a physician injected some medicine into her hip, and following this treatment her headaches were very much better for a time.

Recently she has complained of paresthesia of the postcervical region; her sleep has been interfered with by nervousness, and pains in her neck which required her to frequently change her position. In the morning she is not rested. Her mother states that her condition is the result of her being a "spoiled child and growing too rapidly." Her nervousness was supposed to have been an inheritance from her mother, and her mother's nervousness was induced by the worry and strain of her husband's long illness-a highly reasonable explanation. What were the grounds for suspecting syphilis? Out of a group of 100 people she would have been the last one suspected of having hereditary syphilis, as far as her appearance went. She was a strikingly handsome woman, very tall and mentally alert. Her unusual height - she was over 6 feet - recalls to mind that Fournier, who recognized the syphilitic origin of tabes and paresis many years ago, likewise stated that gigantism and dwarfism were commonly the result of hereditary syphilis.

Dr. Swett found considerable thickening and marked restriction of lateral movement of several cervical spines, which he diagnosed as a probable specific spondylitis; otherwise the physical examination was negative.

The patient was the fourth of five children. One died in infancy. Two married sisters and a bachelor brother are very nervous. One of the sisters is exceedingly so, and also suffers severely from headaches, spending a large part of her time in various institutions taking cures. The provisional diagnosis of hereditary syphilis would probably not have been made, however, except for the fact that her father (No. 2, Chart 1) had died at 47 from tabes, from which he had suffered for twelve years. 
Her mother (No. 1, Chart 1), who is living, formerly suffered from headaches, and is addicted to alcohol.

Notwithstanding her negative Wassermanns and inconclusive luetin reactions, she was given injections of mercuric salicylate by Dr. McKendree and subsequently by her physician in New York, with marked relief of her symptoms.

Had the father died of some acute iliness or an accident before tabes had bectr recognized, the chief key to the problem would have been lacking; yet the extreme nervousness in the brother and sister should suggest their careful examination for some dystrophy of hereditary syphilis.

Two years ago I reported a similar case; a man, aged 36 , whose father had tabes, obtained complete relief from severe headaches and many neurasthenic symptoms following salvarsan and mercury, though his Wassermann was constartly negative. A third case has recently been seen. A middle aged woman whose father had died from tabes experienced great relief from headaches of years' duration following specific treatment. She also had a negative Wassermann.

CAst 2.-A married woman of 37 (Chart 2, No. 15) complained of burning and pressure on the top of her head and of a burning at the tip of her iongue, which symptoms had beein present for ten years. For many years her endurance lad been poor, and often after the day's work she would have to let her hair down because the burning and pressure on the top of her head was so severe. Sometimes she wonld suffer from slight vertigo. Her discomfort was especially marked at the time of mensiruation. For years she had becn more or less disinclined to social activities becalise of general weakness and the above mentioned symptoms. She had been assured that they were due to "uric acid poisoning," and had been on a meat free diet for the past year. No relief, however, followed this abstinence from meat. Her only pregnancy had resulted in a miscarriage.

The patient was a large, fine looking woman presenting no stigmata whatsoever of hereditary syphilis. Physical examination was negative except that there was a slight hypertension-systolic blood pressure 140. The urine contained the smallest possible trace of albumin. The Wassermann was negative. The family history at first appeared to be entirely negative. Her mother died of cardiac dilatation following pneumonia, her father from a tumor of the throat. She has two living sisters, one in good health, the other a semi-invalid from "too much uric acid." Two brothers are living and well, and a brother died from heart disease. Certainly a negative family history. A different picture is obtained, however, when one makes an intensive study of the brothers and sisters and of the preceding generations. In the first place, the sister who suffered from "uric acid poisoning" (No. 14) had a systolic blood presstre of about 260. The other sister (No. 13), who appeared well, had a systolic pressure of about 170 . Both had negative Wassermanns. The latter as a child had an ulcer of the rectum which healed slowly and left a stricture. One living brother (No. 17), who was not examined, is stated to suffer from a chronic "sore" near the anus and periodically the soles of his feet "peel off." A third brother (No. 18), is apparently in good health. The brother who died suddenly at 16 of heart discase (No. 16), hat never suffered from "rheumatism," which is suggestive of syphilitic myocarditis. The mother had four unmarried sisters and one brother. One sister (No. 5) was found to have hypertension and had had several strokes of apoplexy. A second (No. 6), is apparently in good health; a third (No. 8), who was a seven months baby, was not examined, but is said to suffer a great deal from dyspnea, which is suggestive of cardiovascular disease. The fourth sister (No. 7) died at 38 of heart disease. She was unmarried and had not had rheumatism. A maternal brother (No. 4) died at the age of 17 of apoplexy. There were also one miscarriage and two stillbirths.

In the preceding generation, that is, the grandparents of the patient with the burning tongue, the grandmother (No. 1) died at 64 of apoplexy and the grandfather (No. 2), at the same age of "fatty" heart. It is extremely suggestive that the cardiovascular disease which was present in three generations was due to syphilis.

The patient with the burning tongue and pressure on the top of her head was put on injections of mercury and potassium iodid, and promptly and completely recovered from her symptoms, which have not recurred for a period of two and one half years. Since the treatment she has become the mother of twins.

CASE 3.-An unusually alert, keen man of 30 (No. 11, Chart 3 ), became dazed while riding in the cars one day. On reaching home he vomited and had several severe convulsions, involving his whole body. For several days thereafter he was completely disoriented; then for a number of weeks he was listless and disinterested in his affairs, and from time to time he was exceedingly nervous. During the succeeding months he had many momentary lapses of consciousness. Hc would be talking with a man, and suddenly realize that this man had left and another had taken his place, but he had no recollection of the one leaving or the other coming in. Once at dinner when a plate of food was passed to him he asked "what is this for?" but instantly realized it was his dinner.

For a year prior to this illness he had been under a peculiarly severe nervous strain. Two or three times in previous ycars he had some sort of brief sickness apparently depending on constipation, from which he suffered. He was a slender, cnteroptotic type of individual presenting no signs of hereditary syphilis. (The scapulae were not noted.) He gave a negative Wassermann at two different laboratories, and his spinal fluid was reported as negative. The Lange test was not done. Nevertheless, from an intensive study of the family history, I felt that the underlying cause of his attacks of

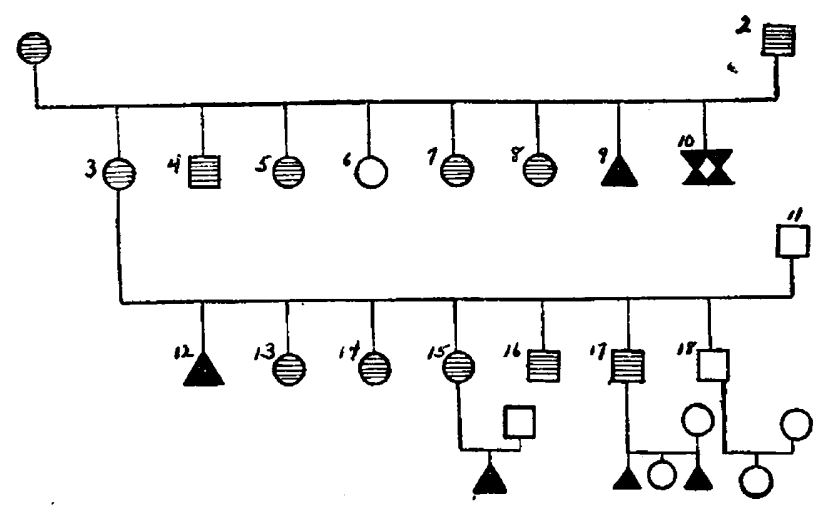

Chart 2.-Heredity chart, Family 2: 15, neurasthenic, aged 39 , Wassermann reaction negative; $13, a, 39 ;$ hypertension; stricture of rectum as girl; Wasscrmann reaction negative; $14, a, 43$; hypertension; Wassermann reaction ncgative; 16 , died at 16 , of "heart disease"; no "heumatism; 17, $a, 37$; not examined; a "sore" near anus; periodically "sheds" skin of soles; $18, a, 36$; apparently well; Wassermann reaction negative; $3, d, 50$, mother of preceding; cardiac dilatation following pneumonia; 4, mother's brother; died of "apoplexy" at 17; 5, sister, died at 38 of "heart disease"; no rheumatism; $6, a, 63$; hypertension; several strokes of apoplexy; Wassermann reaction negative; $7, a, 60$; apparently well; Wassermann reaction negative; $8, a, 58$; was a seven months' baby; not examined; from history, probably hypertension; 10 , stiliborn twins; 1 , maternal grandmother of 15 , died at 64 of apoplexy; 2 , husband of 1, died at 64 of "fatty heart."

petit mal was probably hereditary syphilis, and advised specific treatment.

The father died at 52 (No. 2) of pneumonia. The mother (No. 1) had hypertension for years, dying of uremia at 70 .

In the first place it is significant that out of thirteen pregnancies four were miscarriages and four died in infancy. The oldest son (No. 3) escaped a prenatal infection only to acquire one later in life. The oldest daughter (No. 7) appeared to be well, but was not examined. The next oldest, an unmarried woman of 40 (No. 8), is said to have been delicate as a child. It is noteworthy that the pregnancy preceding the birth of this child resulted in a miscarriage and that three of the four succeeding pregnancies were likewise miscarriages; the fourth child died in infancy. At 12 she was very anemic. In her school work she was not up to grade, as she had diffculty in "grasping things," as she expressed it. For this reason a private tutor was provided, but she made very little progress because she was unable to concentrate her attention on what her teacher was saying. At 24 years of age she had a very severe attack of "nervous prostration." She cried much at this time, and thought people were talking ahout 
her, making unjust accusations against her character. She spent a month in bed, and ever since she has been extremely sensitive about being with people and has been more or less of a recluse. Nine years ago while on a shopping tour her legs began to tremble. She was taken home and was given a hypodermic and the twitching disappeared in about half an hour. For about six months the left side of her face would twitch; it was called "chorea."

Menstruations have been normal, but for about a year were preceded by an uncontrollable attack of "ugliness," as she described it. At these times she could not control herself, and several times she has required morphin. She is con-

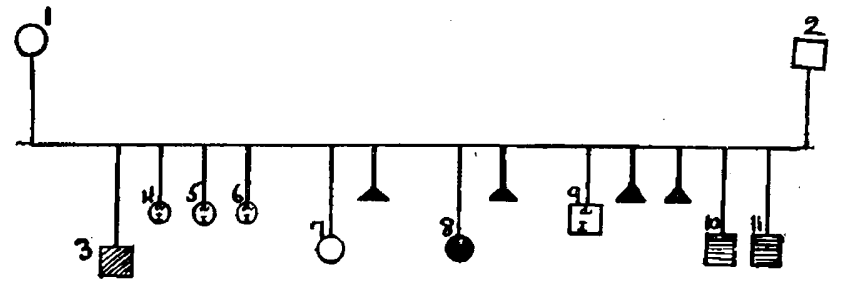

Chart 3.- Heredity chart, Family 3: 1, hypertension, died at 70 of uremia; 2 , died at 52 of pneumonia; 3 , hypertension; diabetes; acquired syphilis; $4,5,6$, 9, died in infancy; $7, a$, well; not examined; $8, a$ 39 , chorea; retarded development; Wassermann reaction $++; 10, a, 34$ neurasthenic; visceroptosis; general pains; prematurely old; Wassermann reaction negative; $11, a, 30$; petit mal; Wassermann reaction negative; spinal fluid negative.

sidered incapable in the household, and is not able to assume any responsibility. Her acquaintances consider her "peculiar." The family appears to be of the opinion that she is naturally disagreeable, and that if she really tried she could be like other people. She has been almost constantly under the care of a nerve specialist. The last few years she has been less nervous, though she is still far from normal. She is a tall woman, and appears to be in good health. It was not possible to make a physical examination. The Wassermann reaction was two plus (50 per cent. inhibition).

The next youngest brother, aged 34 (No. 10), has always been a weakling. I first saw him in May, 1911, at which time he complained of stomach trouble and dizziness with gas after meals, and suffered with constipation. His tongue was "parched on awakening" and while he did not belch, he had a "continuous flow of foul gas" and also "trembling in his stomach." He was also a slender enteroptotic individual, sallow of complexion, delicate in appearance and with all the earmarks of a neurasthenic. $\mathrm{He}$ was put on a diet for constipation, given olive oil injections and exercises, and he improved considerably. For a time he had some mucus in his stools accompanied by cramps, but this finally disappeared. His whole demeanor, however, was one of listlessness, and he goes about most of the time as though in a trance. He is prematurely gray, and looks careworn and old.

It did not occur to me that he might be a heredosyphilitic when I first saw him five years ago, for at that time, in common with most physicians, I thought syphilis always wore the scarlet letter. His Wassermann reaction was negative a year ago, but he was put on mixed treatment, and at the end of three weeks his older sister volunteered the information that she had "never seen such a change in any one in such a short time." She said, "He is awake in the morning at the table; he reads the paper, seems alert and complains of no aches or pains. Prior to this his only conversation had been about his ill health." She also stated that he would go to business where formerly after breakfast he would sit down and go to sleep. She seemed to think there was some possibility that he might amount to something in business, so great was his improvement The youngest son, the patient who suffered from the attacks of petit mal, has already been described. He was seen by two New York consultants, a neurologist and a syphilologist both of national repute, who saw no reason for assuming a syphilitis basis for the attacks; "Were not all the tests negative?" Quite naturally this family passed from my observation.

$C_{A \bar{S}}$ 4.-A married woman aged 35 (No. 20, Chart 4), somplained of extreme nervousness. As a child she was very nervous, and would often awake screaming at night, fearing some one was in her room. Only when her father slept in her rocm, between her bed and the door, was she reassured. In childhood she suffered from pain in her right leg. This pain was always along the shaft of the bone, and never in the joint. For one year she had daily massage without benefit. Mud baths and hot salt rubs were also tried, but with no relief. Part of the time she was under the care of the physician to the royal family of Sweden. Tuberculosis of the bone was diagnosed, and when she was about 12 years old several operations were -performed on the right leg below the knee, and also above the ankle and along the femur. She continued to have pains in her right leg, however, which were always most severe at night. For years she has slept poorly, partly because of nervousness, but largely as a result of the "rheumatism" in her leg. Walking about would often stop these pains, and nearly every night for years she has gotten up and walked the floor, often dozing off while walking, and waking as she stumbled over something. She had very poor endurance and occasional night sweats.

Six years ago, as the result of a fall, the right knee was injured and the patella is now firmly adherent to the tibia. The patient was so nervous that it was difficult for her to give the facts of her history. She presented no signs of hereditary syphilis. Teeth, palate and scapulae were normal. The pupils also were normal; left knee jerk very active, right not obtained, owing to the deformity resulting from the injury six years ago. There were several scars along the right femur and the tibia and over the lower third of the tibia tenderness was elicited.

The history, then, was that of a very nervous child with some disease of the bones of the right leg. This child develcped into an unstable, nervous woman who slept poor'y, complained of weakness, pain in her right leg and occasional night sweats. This was not the history of hereditary syphilis, surely, nor did the physical examination suggest it. The family history, moreover, is chiefly remarkable in that a large number died of tuberculosis ("TB," Chart 4). Her mother, maternal grandmother, maternal aunt and two uncles, two sisters and two brothers had all suffered from tuberculosis. Questioning, however, developed other symptoms that could not be attributed to tuberculosis.

While her mother (No. 3) died from tuberculosis, she suffered for many years from such headaches that she frequently would say she could stand the cough if the headaches would only stop. The mother's sister (No. 4) also had severe headaches, as did the maternal (No. 1) grand.

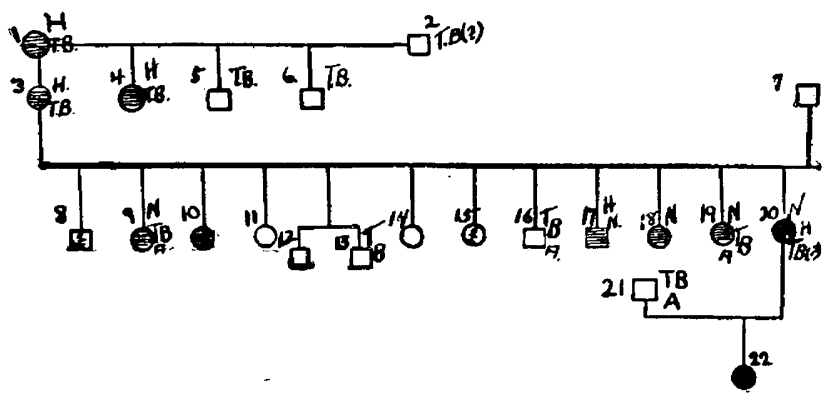

Chart 4.- -Heredity chart, Family 4: 1, severe headaches; died at 60 of tuberculosis; $+; 2$, $d$, tuberculosis (?) "old man"; 3 , severe headaches; tuberculosis at 30 ; died at $64 ; 4$, headache; died of tuberculosis at $60 ;+; 5,6$, died of tuberculosis; $7, d, 60$, cancer of the stomach 8, 15, died in infancy; 9, chorea; extremely nervous; strabismus alcohol; died at 45 of tuberculosis; $10, a, 50$, blind several months; 11 very myopic; died at 4 of "tumor"; 12 , alive, well; $13, d$, tuberculosis; $14, d$ "tumor of neck"; $16, a$, tuberculosis; alcohol; $17, a$, very nervous; "terrible headaches"; 18 , a, very nervous; 19 , very nervous; alcohol; died at 19 of tuberculosis; $20, a, 30 ;+$; very nervous; headache; bone disease (tuberculous?); "rheumatism"; Wassermann ++++ ; cure (?) by treatment; 21 , husband of 20 ; Wassermann negative; 22 , aged 11; interstitial keratitis; deaf; Wassermann ++++ ; "cured" (?) by treatment.

mother. Among her own brothers and sisters four are exceedingly nervous $(9,17,18,19)$, one has severe headaches, one strabismus, another was blind for several months (keratitis?), another is very myopic, and three have been alcoholic since early life (Nos. 9, 16 and 19). 
It is unlikely that I would have thought of hereditary syphilis in connection with this patient had it not been that her only daughter (No. 22), a large, well developed girl of 13 , had been a patient of mine with interstitial keratitis and an eighth nerve involvement. This daughter and her mother had four plus Wassermanns, but the father (No. 21) gave a negative test.

The responsc to treatnent confirmed the diagnosis. The patient received a number of injections of salvarsan and for several months took mercuric inunctions. The improvement was so prompt and so marked that she could not understand it. From a high strung woman on the verge of tears she has developed into a perfectly calm self-contained individual entirely free from any suggestion of "nerves."

Six months after the first salvarsan she said that she had not lost one night's sleep since the treatment. A month later, she stated that she was in better health than she ever had been before in her life, and what seemed most surprising was the fact that, notwithstanding several weeks of almost constant rain, she had had absolutely no rheumatism. This past winter, though she has worked in a little grocery store with scarcely any heat, she has had no recurrence of her pains.

This family illustrates in the first place how deceptive an incomplete family history may be. On the surface it appeared to contain only an unusually large number of cases of tuberculosis; but a complete study reveals certain symptoms that tuberculosis would not explain. It also illustrates the truth of Fournier's contention that hereditary syphilis presupposes to tuberculosis. But most important of all, it illustrates that the study of a child may shed some light on the ill health of a parent.

It is not known through how many generations syphilis can be transmitted. The activity of the process in the daughter with interstitial keratitis, the offspring of a heredosyphilitic mother, was manifestly such an active infection, that there seems little doubt that she could have given birth to syphilitic children. Had the child been a boy it is perhaps possible that he could have passed on the disease to another generation from infection by means of his semen.

During the past year three children have come under ny observation because of a marked nasal catarrh. The discharge was thick and purulent, though not of offensive odor. The Wassermann was strongly positive in two. 'The third, the son of a syphilitic, was not tested, but he was put on inunctions of mercury with immediate anci marked improvement. An equally satisfactory result was obtained in one of the other cases. The third child did not receive treatment. The following case is jllustrative of what may result when such a condition is unrecognized:

CAss 5.-An unmarried girl of 18 (No. 35, Chart 5), was referred to me three years ago by a nose and throat specialist who suspected she might have a syphilitic process of the interior of the nose. She was a pretty buxom girl with excellent teeth, a normal palatal arch, and presenting absolutely no signs of hereditary syphilis. There was a purulent foul sinelling discharge from the nose, which was increased in width at its base. She gave a strongly positive Wasscrmann. The doctor who referred her to me suspected she was an immoral girl, and 1 concurred with him in his opinion. It was not until over a year later that I made a special study of her own early history and that of her family. When she was 8 or 10 years of age she was a mouth breather; the condition was not improved by the application of adhesive plaster on her mouth, and finally at about the age of 15 , her adenoids were removed. She still continued to have a nasal discharge, and received treatment from various specialists and clinics. She was at first told it was hay-fever and that in the fall it would probably go away. The nasal discharge increased, however, and she wotld have crusts form in the interior of the nose.
Shortly before I saw her a physician had told her she had probably contracted a contagious disease from a drinking cup, but the nature of the disease she was entirely ignorant of. One month previously, her nose had begun to swell. Over a year later a sister of this girl, aged 23 (No. 32), came to me complaining of transient swelling of her lips (angioneurotic edema?) and nasal catarrh. She was always "catching cold in her head." Her endurance had always been poor. Although 23 years old, she did not appear to be either mentally or physically more than 18 . Except that she was a slender, frail, immature girl, her physical examination would be called negative but for her teeth. She had probably had hypoplasia of all six year molars; they were extremely yellow, and the lower incisors were yellow at the tips. The Wassermann was three plus.

Several months later another sister, aged 22 (No. 33), consulted me because of sudden "cramps" in the calves of the legs (intermittent claudication?). Following an illness at the age of 12 , said to have been typhoid, she had ulcers on her legs. She was exceedingly nervous, and all of her life had suffered more or less from headaches, chiefly actoss the forehead and invariably worse at her menstruation periods. Her Wassermann was strongly positive.

A third sister, aged 19 (No. 34), suffered from epilepsy. She, too, had been subject to severe headaches, and in childhood had stffered from severe pains in her legs, referred

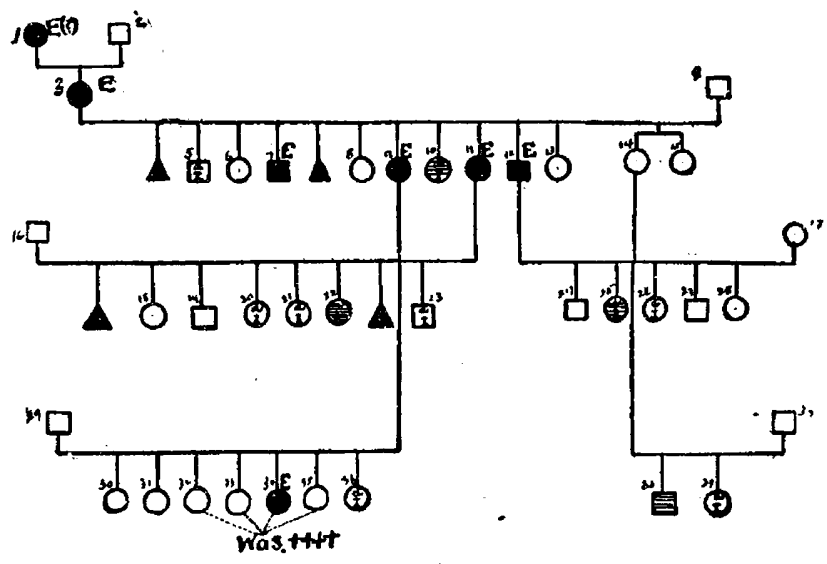

Chart 5.-Heredity chart, Family 5: 1, d, 84, probably epileptic; 2 $d, 80 ; 3, a$, epileptic; $4, d, 62$, arteriosclerosis; 6 , $a$, well, $60 ; 7$, epileptic $d$, 40, heart and kidney disease; $8, a$, well, 50; 9, $a$, epileptic; married 29 ; a drunkard and suicide; positive Wassermann reactions from thei children, 32, 33, 34 and 35 , and 34 is epileptic; 10 , teeth at 1 week dropsy; died at seventh year; 11, $a$, epileptic; had two miscarriages; three children died in infancy; a daughter, (22), arrested development 12 , $a$, epileptic; Wassermann reaction negative; 13, $d$, Bright's disease aged $23 ; 14, a$, said to be well; her son, 38 has a very large head and is mentally deficient; $15, d, 21$, cause (?); $5,20,23,25,26,36,39$ died in infancy; $24, a$, frail, Wassermann reaction negative; 25 , "blue baby", 28 , very frail.

to as "growing pains." She had always been nervous. The Wassermann test showed complete inhibition. Following the use of mercury inunctions, the nervousness was notably less.

This family, then, presented four girls, one of whom had rhinitis, three were very nervous, one was an epileptic, one gave evidence of an arrest of development both physically and mentally, and two had headaches.

As the father was a drunkard and suicide and the mother an epileptic, the so-called neuropathic heredity would explain all of the symptoms, save the nasal lesion, were it not for the positive Wassermanns. It is quite possible that the mother contracted syphilis from her husband. There is considerable, on the other hand, to suggest that the mother may have been heredosyphilitic.

One maternal aunt (No. 11) and two maternal uncles (Nos. 7 and 12) suffered from epilepsy, as well as the maternal grandmother (No. 3), who is still living at the age of 80 . Her health otherwise is excellent, and she is a very active woman. Her mother (No. 1) lived to the age of 84 , and is also stated to have suffered from "fits." One maternal aunt, (No. 11), and uncle, (No. 12), and the grandmother gave negative Wassermann tests.

It was not possible to make a complete study of the chil- 
dren of the other members of the family. A daughter (No. 22) of one of the epileptic aunts, however, was immature in appearance and had abnormal teeth. This aunt had also had two miscarriages and lost four children in infancy or childhood. Another sister (No. 14) has one living child of 6 years who has a very large head and is mentally deficient. Another of the mother's third sisters (No. 10) had teeth at one week and died of dropsy at 7 years of age. Two sons (Nos. 7 and 13) died from kidney disease.

Care must be exercised in differentiating between what might be called incidental syphilis which merits consideration but no therapy, at least for the moment, and what we may designate as pertinent syphilis.

As an example of the former, mention might be made of a case of pneumonia recently seen in consultation. The patient, a young woman, had a large bulging forehead. Two sisters had similar foreheads. The mother was prematurely gray and very nervous. The father had a third nerve palsy. It was unnecessary to ask questions or make blood tests to diagnose familial syphilis, but this was purely incidental to her pneumonia. However, should her convalescence be protracted, the underlying hereditary syphilis might become pertinent and her improvement hastened by specific treatment.

The Wassermann test is unquestionably the most valuable laboratory test yet discovered, but to depend on it exclusively is to court disaster. There are three classes of physicians who attach undue importance to this test: first, the lazy physician who would rather some one else would make his diagnosis for him; second, the man incapable of taking a complete history and making a thorough examination, and lastly the type which Christian has so well described as the man who "with but a slight glance at his patient, and no conception of the patient's symptoms, rushes to his laboratory tests with the idea that scientific accuracy increases by the square of the distance from the bedside and by the cube of the time spent in carrying out a test."

To the dictum, "When in doubt have a Wassermann test," we should add, "but first make an intensive study of the family."

\section{ABSTRACT OF DISCUSSION}

Dr. W. W. Graves, St. Louis: I have on several occasions called attention to the importance of studying the whole family where one of its members gives even the slightest indication of syphilis. One of the cases reported by Dr. Stoll, in which he suspected syphilis in the third generation, was brought to him because the patient had interstitial keratitis, and he studied every member of the family and found that the parents and grandparents in that family were syphilitic. Dr. Kaskell, in discussing Dr. Drysdale's paper, stated that a recent study had shown the Wassermann reaction in 40 per cent. of the wives of paretics and tabetics was positive, whereas only a small number of the progeny of these paretics and tabetics gave positive Wassermann reactions. In our study of syphilis we are inclined to rely too much on positive and negative Wassermann or luetin reactions, whereas we should study the family, not only as far as the history of that family is concerned in all its details, but we should. as well, make comparative clinical studies of families. If there is one thing that is particularly characteristic of the progeny of syphilitic parents it is the deviation to be found in such progeny when compared with the parents. I grant that it is common to find children of syphilitic parents who compare favorably with other children of the community, but the only standard we have for the individual is how he compares with his ascendant, and those who are most accessible are the parents, and then a comparison of each child with the other. The characteristic thing of children born of syphilitic parents is that they do not compare favorably with their parents, particularly in their physical endowments and in their resistance to disease. We know how rare are Hutchinson teeth, how infrequent is interstitial keratitis, how rare is deafness without otitis, and how infrequent is the Wassermann reaction, but if we study every member of the family in a comparative clinical way we cannot fail to find gross deviations which demand explanation. The most pernicious effects of syphilis are on the parental germ plasm, from which the individual develops; hence the deviations and the vulnerability to disease of syphilitic progeny.

DR. A. L. Skoog, Kansas City, Mo.: I recently studied an interesting case, a girl of 18 , who five months ago developed a hemichorea involving the right leg, arm and face. It was progressive. Outside of that there were practically no clinical findings; the reflexes were but very little different on the right side as compared with the left. A Wassermann was made on the blood which resulted in a 4 plus positive. The spinal fluid likewise showed a 4 plus positive. There was no lymphocytosis. The globulin content was increased. This girl's father and mother died when young, the patient being the only child. I could not find positive cause of death in either parent, but suspected vascular syphilis. Two sisters on the maternal side are living in the same city and are now being treated for late syphilitic troubles after certain positive diagnosis had been made.

Dr. William Ravine, Cincinnati: I would like to ask Dr. Graves if the scaphoid scapula can still be looked on as one of the stigmata of hereditary syphilis, or if there has been reason to change the view concerning this finding. In the work of examining juvenile delinquents I always look and note the existence or absence of the scaphoid scapula, and very often we find nothing else of value.

DR. W. W. Graves, St. Louis: I have never stated that the scaphoid scapula should be considered a sign, in itself, of congenital syphilis in the individual or of syphilis in his parents. There is but one way to determine its significance, and that is to study every member of the same generation for the scaphoid scapula and what I have called its correlations, plus a similar study of the parents and other ascendants. The scaphoid scapula is of great value as a clew, but as evidence of congenital syphilis it should never be used alone. Since finding the scaphoid scapula eight years ago, and later indicating its clinical significance, I have feared that the profession might use the scaphoid scapula as a pathognomic sign of congenital syphilis, whereas nothing could be further from the truth.

Dr. Henry Farnum Stoll, Hartford, Conn: I want to add my testimony to what Dr. Graves has just said in regard to the scaphoid scapulae. As examining physician of an outdoor school of a hundred pupils, in the course of a year I see a good many children and for over a year I have been on the lookout for scaphoid scapulae. I have been fortunate in having a social worker who has made intensive studies of the families for me and I agree with Dr. Graves that when it is possible to make a complete study of the parents and grandparents, one can nearly always find symptoms or signs strongiy suggestive of syphilis. Occasionally it is the only stigmata. Fournier, who years ago said that partsis and tabes were due to syphilis, also stated that the heredosyphilitics of the weakling group are especially prone to tuberculosis. When they develop this disease it is especially apt to be fatal. A Colorado physician has recently made a special study of a series of cases of tuberculosis that were doing badly and found that a high percentage showed various dystrophies. He did not deduce, however, as I think he should have, that these dystrophies were probably due to hereditary syphilis. We should commence to teach the public that syphilis is exceedingly common and that it is liable to occur in any family. We should teach them to look on syphilis as a misfortune, not as a disgrace, for there are more innocent than there are guilty sufferers. Until we promulgate this idea we shall fall short of solving the problem of syphilis.

Self-Education.-The best part of every man's education is that which he gives to himself.-Sir Walter Scott. 